\title{
Curriculum on Resident Education in Care of Older Adults in Acute, Transitional and Extended Care Settings
}

\author{
Chandrika Kumar ${ }^{1,2}$, Benjamin A Bensadon ${ }^{3}$, Peter H Van Ness ${ }^{1}$, Leo M Cooney ${ }^{1}$ \\ ${ }^{1}$ Dept. of Internal Medicine - Section of Geriatrics, Yale University School of Medicine, New Haven CT, USA \\ ${ }^{2}$ VA Connecticut Healthcare System, West Haven, CT \\ ${ }^{3}$ Department of Integrated Medical Science, Charles E. Schmidt College of Medicine, Florida Atlantic University, USA \\ Correspondence: Chandrika Kumar, Yale University School of Medicine-Section of Geriatrics, 20 York Street, New \\ Haven CT 06520, USA.
}

Received: July 18, 2016

doi:10.11114/jets.v4i9.1742
Accepted: August 9, $2016 \quad$ Online Published: August 31, 2016

URL: http://dx.doi.org/10.11114/jets.v4i9.1742

\begin{abstract}
Most geriatric care is provided in non-hospital settings. Internal Medicine and Family Medicine residents should therefore learn about these different clinical sites and acuity levels of care. To help facilitate this learning, a geriatrics training curriculum for internal medicine residents was developed that focused on cognition, function, goals of care and medication management in both in-hospital and non-hospital settings. Residents rotated through both in-hospital and non-hospital settings as one block rotation. They took a test of geriatric learning before the rotation and then took the same test at the end of the rotation. Residents showed an improvement in several geriatric domains on completion of a combined in-hospital and non-hospital rotation curriculum. We concluded that the development and implementation of a combined rotation curriculum has practical application to resident learning and the potential to improve geriatrics care outside of hospital settings.
\end{abstract}

Keywords: resident education, curriculum, in-hospital and non-hospital settings

\section{Introduction}

This article describes the development and implementation of an innovative geriatrics curriculum for traditional internal medicine residents. A 1980-2014 literature review through Google Scholar and PubMed found several articles on geriatrics curriculums and a few articles which described a combined in-hospital and non-hospital geriatric learning experience for internal medicine residents. (Barbour, Tompkins \& Eisenberg,1987; Duane, et al, 2012; Eugenia, et al, 2014; Faulk, Lee \& Musick, 2012; Jones, Dougherty, Cannon \& Schelbel, 1986; Feigenbaum, Allen \& Brownstein,1981;Steinberg,1984). The unique feature of the curriculum was the incorporation of the non-hospital rotation into an in-hospital rotation, enhancing care continuity and giving residents the opportunity to follow patients from one setting to another. Most often, residents had the opportunity to take care of patients they admitted in the hospital settings through their transition into the non-hospital settings of care.

This rotation includes an in-hospital component (acute care for the elderly unit) and a non-hospital component at several area facilities. It is unique in that the postgraduate year (PGY) 1 residents do both components of the rotation as part of a four-week block rotation. The curriculum enabled postgraduate year (PGY) 1 medical residents to work with geriatrics faculty in the hospital settings, and with adjunct geriatrics faculty in the non-hospital settings, thus providing them with valuable academic and clinical experience with several acute and chronic geriatric conditions.

This curriculum was designed to increase residents' knowledge of and confidence in dealing with geriatric patients in both acute and non-acute settings, and to motivate residents to incorporate geriatric principles of cognition, function, medication management, and goals of care into their own clinical practice when they provide medical care to older adults.

\section{Method}

\subsection{Development of the Geriatrics Curriculum}

The 2011 Accreditation Council for Graduate Medical Education (ACGME) duty hour requirements led to major 
changes (https://www.acgme.org/Portals/O/PFAssets/ProgramRequirements/CPRS_07012016).

The requirements for PGY 1 residents are now even more stringent than before. These changes in resident requirements led the geriatrics faculty to ask:

- How do these changes affect geriatrics education?

- Where should we be teaching medical residents geriatric skills?

- What should we be teaching?

Problem identification

The Yale-New Haven Hospital's acute care for the elderly (ACE) unit, which admits patients over 65, has 22 beds. Existing geriatrics training emphasizes acute hospital/inpatient medicine; almost all the residents' time is spent in hospital settings where the focus is primarily on disease-specific management. There was little exposure to geriatrics learning in non-hospital settings where most care is provided to older adults.

Goal and objectives

The June 2009 Medicare Payment Advisory Commission (MedPAC) report to Congress raised concerns that residents are not currently receiving formal instruction and experience that will allow them to function optimally in the new systems of health care delivery in which most care of older adults is provided in non-hospital settings. In late 2007, a group of academic educators and geriatricians from internal medicine (IM) and family medicine (FM) involved in geriatrics curriculum development undertook to define the minimal and essential competencies in geriatrics. Seven domains were identified for the essential internal medicine/family medicine geriatric competencies: medication management; cognitive, affective, and behavioral health; palliative and end-of-life care; hospital patient safety; complex or chronic illness (es) in older adults; transitions of care; and ambulatory care. (Williams BC, Leipzig. 2010) .The goals of our new geriatrics curriculum were to insure that internal medicine residents develop the knowledge, skills, and attitudes necessary to manage older adults outside acute settings pertaining to the seven domains. The objectives were that, upon completing the non-hospital curriculum, residents should be able to demonstrate knowledge of different methods of cognitive testing and their applications, improve their ability to discuss goals of care for patients with cognitive and functional problems, and enhance their management of medications in patients with limited goals of care.

A self-administered multiple choice presurvey knowledge test (Table 1) was delivered to the residents via email to define the curricular content prior to the start of the rotation. The targeted learners for the implementation and evaluation of the new curriculum were our PGY 1 residents during their geriatrics rotation on the acute care for the elderly (ACE) unit.

Table 1. Pre Survey

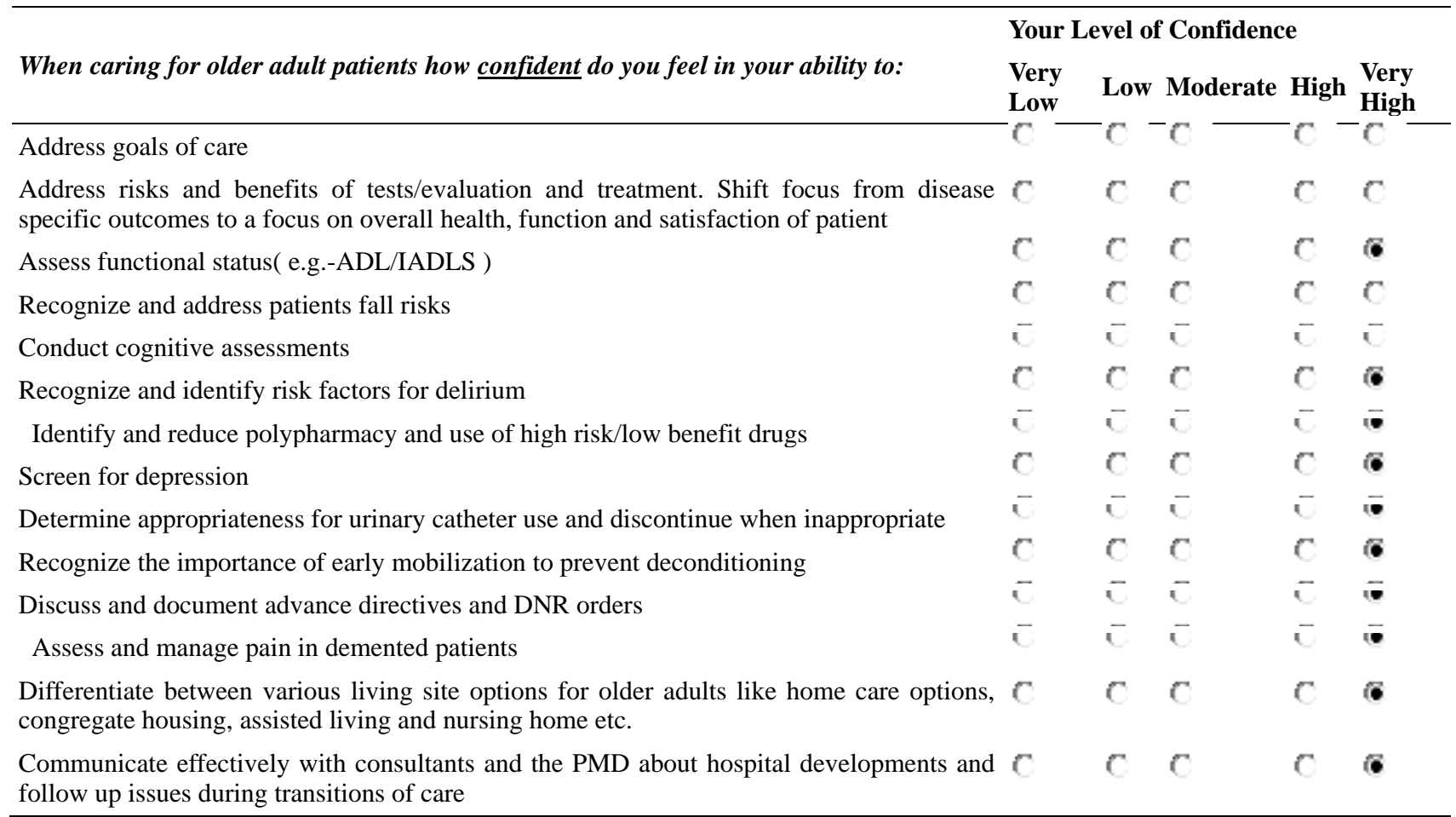


Completing the presurvey was required before the start of the geriatrics rotation. The presurvey was adapted and modified from University of Chicago model known as the "Curriculum for the Hospitalized Aging Medical Patient Evaluation Instrument" (CHAMPS) (Baron, Cook, Levine \& Smith, 2012). We wanted learners to be able to rate on a Likert scale from 1 (least) through 5 (greatest) their confidence in their ability to provide care to an older adult with the explained geriatric syndromes as outlined in the presurvey (Table 1).

At the completion of the geriatrics rotation, the residents were asked to rate their confidence in the same skill areas included in the pre-survey. Confidence and other personal beliefs have been linked with actual behavior for decades. (Bensadon BA. 2015)

\subsection{Content of Geriatrics Curriculum}

The geriatrics curriculum included such topics as goals of care, understanding of alternate living options for older adults, medication management, cognitive and functional limitations, and safe discharge planning (Appendix. Curriculum)

We worked to ensure that residents were proficient in the use of simple cognitive screening instruments like the mini cognitive assessment (Minicog) (Borson, Scanlan, Chen \& Ganguli, 2003) in a hospital setting, and more in-depth testing like the Saint Louis University Mental Status Examination (SLUMS) (Tariq,Tumosa, Chibnall, Perry \& Morley,2006) MOCA (Montreal Cognitive Assessment) (Nasreddine et al. 2005) and executive interview (EXIT) (Royall , Mahurin and Gray,1992) in non-hospital settings.

Functional assessment training included grip strength (Bohannon,2008), and the "get up and go" (Nordin, Lindelof, Rosendahl, Jensen \& Lundin-Olsson,2008.) and "timed up and go" tests (Podsiadlo, Richardson, 1991 ).These physical exam maneuvers were demonstrated during hospital and non-hospital teaching rounds. Medication management was included as a core part of the curriculum for both in-hospital and non-hospital settings. The in-hospital rotation focused on more adverse effects of medications, while the non-hospital rotation focused on patient needs and evidence bases for medication use. The residents' experiences in both types of settings taught them the importance of complete information in transitions of care documentation, the limitations on care available outside of the hospital, and the financial and regulatory aspects of the health care system. The methods used to deliver the above content were case-based discussions and bedside teaching rounds. These were facilitated by the geriatrics attending on service. Clinically relevant handouts were made available to the residents via email.

\subsection{Implementation}

With this new non-hospital aspect of the rotation, changes were needed to the existing structure of the acute care for the elderly (ACE) rotation. Instead of the customary two senior residents and two PGY 1 residents, we incorporated three PGY 1 residents into the rotation. The attending was one of the geriatrics faculty members from the section of Geriatrics; there was also a co-attending who was a hospitalist.

It was decided that the geriatrics rotation should be a combined rotation with an in-hospital and a non-hospital component, and that this combined rotation would be given during the PGY 1 year so that residents could acquire geriatrics skills early in their training.

The three PGY1s took turns completing the non-hospital component as part of their ACE rotation. So, while two were in the hospital setting, one PGY 1 was at a non-hospital facility.

\subsection{Non-hospital Rotation Sites}

The teaching venues were chosen to satisfy the following criteria: a large number of geriatric patients; reasonable driving distance from the main hospital; availability of public transportation; and the presence of attendings with board certification in geriatrics. The sites chosen were three sub-acute rehabilitation and long term care centers; one geriatric assessment center; two continuing care retirement communities; one adult day care; and one geropsychiatric unit located in a long-term care facility. Once the locations were established, we determined which geriatric attending would serve as the primary teacher at each location.

The non-hospital rotation provided an excellent learning experience when residents received a patient as a transfer for sub-acute rehabilitation from the hospital. This gave them an opportunity to review discharge summaries, medications, and lab results, and provide feedback to the discharge team on what changes could have been made for a safe patient discharge.

\section{IRB statement}

This research is exempt from the institution's IRB review under federal regulation 45 CFR 46.101(b) (1).

\section{Results}

Quantitative and Qualitative Analysis 
For the quantitative analysis, overall mean values for the results of the pre- and post-tests were calculated .The overall pre-test mean was then subtracted from the overall post-test mean to obtain the difference between the two overall tests results. To assess whether this difference was statistically significant at the 0.05 level of significance for a two-sided test, a Student's t location test was performed with the null hypothesis specifying a difference of zero. SAS ${ }^{\circledR}$ version 9.4 statistical software was used to analyze the data.

For the qualitative analysis, the residents were asked an open-ended question about the supplementation of the in-hospital rotation with a non-hospital rotation, and the geriatric learning that accrued from the combined rotation curriculum. Reponses were recorded and analyzed for thematic content

The individual pre- and post-test means are reported in Table 2. The overall pre-test mean was 3.315, the overall post-test mean was 4.057 , and their difference was 0.742 , with this positive difference indicating statistically significant improved performance on the post-test $(\mathrm{t}=12.624, \mathrm{p}<0.0001)$.

Table 2. Pre and Post test means

\begin{tabular}{|c|c|c|c|c|c|c|c|c|}
\hline Resident & Post Mean & Pre Mean & $\begin{array}{l}\text { Post } \\
\text { Difference }\end{array}$ & Pre & Resident & Post Mean & Pre Mean & $\begin{array}{l}\text { Post Pre } \\
\text { Difference }\end{array}$ \\
\hline 1 & 4.23077 & 3.76923 & 0.46154 & & 30 & 4.00000 & 3.69231 & 0.30769 \\
\hline 2 & 4.46154 & 3.00000 & 1.46154 & & 31 & 4.00000 & 3.76923 & 0.23077 \\
\hline 3 & 4.07692 & 3.38462 & 0.69231 & & 32 & 3.84615 & 2.53846 & 1.37069 \\
\hline 4 & 4.15385 & 3.69231 & 0.46154 & & 33 & 3.92308 & 3.76923 & 0.15385 \\
\hline 5 & 4.19231 & 3.23077 & 0.96154 & & 34 & 4.00000 & 3.84615 & 0.15385 \\
\hline 6 & 3.92308 & 3.65385 & 0.26923 & & 35 & 3.92308 & 2.30769 & 1.61538 \\
\hline 7 & 4.15385 & 3.76923 & 0.38462 & & 36 & 3.84615 & 3.00000 & 0.84615 \\
\hline 8 & 4.00000 & 2.76923 & 1.23077 & & 37 & 3.76923 & 3.53846 & 0.23077 \\
\hline 9 & 4.46154 & 4.07692 & 0.38462 & & 38 & 3.76923 & 3.38462 & 0.38462 \\
\hline 10 & 4.15385 & 2.84615 & 1.30769 & & 39 & 4.00000 & 3.69231 & 0.30769 \\
\hline 11 & 4.38462 & 3.03846 & 1.34615 & & 40 & 3.69231 & 3.53846 & 0.15385 \\
\hline 12 & 4.23077 & 3.00000 & 1.23077 & & 41 & 4.00000 & 3.15385 & 0.84615 \\
\hline 13 & 4.76923 & 3.84615 & 0.92308 & & 42 & 3.76923 & 2.61538 & 1.15385 \\
\hline 14 & 4.15385 & 3.92308 & 0.23077 & & 43 & 4.30769 & 2.92308 & 1.38462 \\
\hline 15 & 4.30769 & 3.30769 & 1.00000 & & 44 & 3.61538 & 2.92308 & 0.69231 \\
\hline 16 & 4.23077 & 3.23077 & 1.00000 & & 45 & 3.84615 & 3.00000 & 0.84615 \\
\hline 17 & 4.46154 & 4.23077 & 0.23077 & & 46 & 3.92308 & 3.84615 & 0.07692 \\
\hline 18 & 4.46154 & 3.73077 & 0.73077 & & 47 & 3.84615 & 2.69231 & 1.15385 \\
\hline 19 & 4.23077 & 3.00000 & 1.23077 & & 48 & 3.92308 & 3.84615 & 0.07692 \\
\hline 20 & 3.92308 & 3.07692 & 0.84615 & & 49 & 4.00000 & 3.38462 & 0.61538 \\
\hline 21 & 4.30769 & 3.61538 & 0.69231 & & 50 & 3.76923 & 3.15385 & 0.61538 \\
\hline 22 & 4.30769 & 4.15385 & 0.15385 & & 51 & 3.61538 & 3.00000 & 0.61538 \\
\hline 23 & 4.00000 & 3.15385 & 0.84615 & & 52 & 3.92308 & 2.69231 & 1.23077 \\
\hline 24 & 3.76923 & 3.23077 & 0.53846 & & 53 & 4.00000 & 3.07692 & 0.92308 \\
\hline 25 & 4.23077 & 3.92308 & 0.30769 & & 54 & 4.15385 & 3.61538 & 0.53846 \\
\hline 26 & 4.15385 & 3.46154 & 0.69231 & & 55 & 4.15385 & 2.92308 & 1.23077 \\
\hline 27 & 4.15385 & 3.84615 & 0.30769 & & 56 & 3.76923 & 3.23077 & 0.53846 \\
\hline 28 & 4.07692 & 3.07692 & 1.00000 & & 57 & 4.07692 & 2.38462 & 1.69231 \\
\hline 29 & 3.84615 & 2.38462 & 1.46154 & & & & & \\
\hline
\end{tabular}

\section{Discussion}

This article demonstrates that appropriate quality and quantity of geriatrics training can be provided at both inpatient acute hospital training sites and non-hospital training sites like ambulatory, sub-acute and chronic care settings. We used the six-step approach to curriculum development in:

1. Problem identification (lack of non-hospital geriatric learning sites)

2. Targeted needs assessment (assessed geriatrics learning needs of PGY 1 learners)

3. Determining goals and objectives (what do we want learners to be competent in upon completion of the rotation)

4. Educational strategies (what should be learned and where)

5. Implementation (identified and addressed barriers and continue to refine the curriculum over successive cycles)

6. Evaluation and feedback (post survey). ( Kern, Thomas \&Hughes, 2009)

After learning from our resident physicians what they felt they needed to know about caring for older individuals, the geriatrics faculty recognized that they had to provide training opportunities in settings such as assisted living facilities, 
continuing care retirement communities, nursing homes, and rehabilitation facilities.

There were some limitations to this study. While we believe that a combined rotation including both inpatient and outpatient activities is best for training resident physicians in caring for older adults, the rotation was not easy to implement and maintain. We had to be mindful of the extensive clinical responsibilities of those teaching the residents at non-hospital sites. Transportation to these sites was sometimes a challenge. Coordinating the sites and the schedules of both the residents and faculty physicians was sometimes daunting. The curriculum was implemented in only one institution and only PGY 1's rotated through the different sites of care. Also, the evaluation of resident learning focused on their confidence about things they had learned but did not objectively assess their increased knowledge.

\section{Conclusions}

Our study demonstrates the feasibility of creating a combined curriculum encompassing geriatric care in both hospital and non-hospital settings. The development and implementation of a combined rotation curriculum where residents go back and forth between acute hospital and nonhospital settings has practical application to resident learning, and the potential to improve the care provided to older adults outside of hospital settings.

\section{References}

ACGME, Common program requirements: general competencies. Feb 13, 2007. Approved by the ACGME Board. Accessed online Jan 2016

Barbour, G. L., Tompkins, M. J., \& Eisenberg, M. G. (1987). An integrated geriatric training experience. Gerontol Geriat Educ; Spring-Summer, 7(3-4), 29-41.

Baron, A., Cook, S., Levine, S., \& Smith, S. (2014). Online access on Sept 10th 2014.CHAMP Curriculum for the Hospitalized Aging Medical Patient evaluation instrument; University of Chicago Division of the Biological Sciences the Spritzer School of Medicine. Donald Reynolds Foundation. POGOe Id: 20055. Posted: 08/07/2009. Updated:07/09/2012

Bensadon, B. A. (2015). Attitudes, Beliefs, and Behavior. Psychology and Geriatrics: Integrated Care for an Aging Population, 45-67. San Diego, CA: Elsevier. http://dx.doi.org/10.1016/B978-0-12-420123-1.00003-4

Bohannon, R. W. (2008). Hand-grip dynamometry predicts future outcomes in aging adults. 2008. J. Geriatr. Phys. Ther., 31, 3-10. http://dx.doi.org/10.1519/00139143-200831010-00002

Borson, S., Scanlan, M., Chen, P., \& Ganguli, M. (2003). The Mini-Cog as a screen for dementia: validation in a population - based sample. Journal of the American Geriatrics Society, 51, 1451-1454. http://dx.doi.org/10.1046/j.1532-5415.2003.51465.x

Duane, T. M., et al. (2012). Geriatric education for surgical residents: identifying a major need. Am. Surg. Jul., 77(7), 826-831.

Eugenia, L. S., et al. (2014). Assessing Effectiveness of a Geriatric Rotation for Second -Year Internal Medicine Residents. J. Grad. Med. Edu., 6(3), 521-525. http://dx.doi.org/10.4300/JGME-D-13-00344.1

Faulk, C. E., Lee, T. J., \& Musick, D. (2012). Implementing a multidimensional geriatric curriculum in a physical medicine and rehabilitation residency program. Am. J. Phys. Med. Rehabi., 91(10), 883-889. http://dx.doi.org/10.1097/PHM.0b013e318264408f

Feigenbaum, Z. L., Allen, L. C., \& Brownstein, H. (1981). Geriatric Education in a Teaching Hospital: The role of Geriatric Services. West J. Med., 135(6), 492-496.

Jones, J., Dougherty, J., Cannon, L., \& Schelble, D. (1986). A geriatric curriculum for emergency medicine training programs. Ann. Emerg. Med., 15(11), 1275-1281. http://dx.doi.org/10.1016/S0196-0644(86)80608-4

Kern, D. E., Thomas, P. A., \& Hughes, M. T. (2009). Curriculum Development for Medical Education. A six step approach. Appendix A. Longitudinal program in curricular development.217-230.

Nasreddine, Z. S, et al. (2005). The Montreal Cognitive Assessment, MoCA: A Brief Screening Tool for Mild Cognitive Impairment. Journal of the American Geriatrics Society, 53(4), 695-699. http://dx.doi.org/10.1111/j.1532-5415.2005.53221.x

Nordin, E., Lindelöf, N., Rosendahl, E., Jensen, J., \& Lundin-Olsson, L. (2008). Prognostic validity of the Timed Up-and-Go test, a modified Get-Up-and-Go test, staff's global judgement and fall history in evaluating fall risk in residential care facilities. Age and Ageing, 37(4), 442-448. http://dx.doi.org/10.1093/ageing/afn101 
Podsiadlo, D., \& Richardson, S. (1991). The timed 'Up \& Go': A test of basic functional mobility for frail elderly persons. Journal of the American Geriatrics Society, 39(2), 142-148. http://dx.doi.org/10.1111/j.1532-5415.1991.tb01616.x

Royall, D. R., Mahurin, R. K., \& Gray, K. F. (1992). Bedside Assessment of Executive Cognitive Impairment: The Executive Interview. Journal of the American Geriatrics Society, 40, 1221-1226. http://dx.doi.org/10.1111/j.1532-5415.1992.tb03646.x

Steinberg, F. U. (1984). Education in geriatrics in physical medicine residency training programs. Arch. Phys. Med. Rehabl., 65(1), 8-10.

Tariq, S. H., Tumosa, N., Chibnall, J. T., Perry, M. H., \& Morley, J. E. (2006). Comparison of the Saint Louis University Mental Status Examination and the Mini Mental State Examination for detecting dementia and mild neurocognitive Disorder a pilot study. Am. J. Geriat. Psychiat., 14, 900-910. http://dx.doi.org/10.1097/01.JGP.0000221510.33817.86

Williams, B. C., et al. (2010). Medicine in the 21st century: recommended essential geriatrics competencies for internal medicine and family medicine residents. J. Grad. Med. Educ., 2(3), 373-383.

http://dx.doi.org/10.4300/JGME-D-10-00065.1

This work is licensed under a Creative Commons Attribution 3.0 License. 